\title{
Report on EFSUMB 2013 activities from EFSUMB President Christoph F. Dietrich
}

It is my pleasure to report on the important activities of last year and welcome the new year of ultrasound 2014 .

The EUROSON congress took place in Stuttgart, Germany. This was a very successful event, joining the "Dreiländertreffen" of the German speaking countries with EUROSON, our multidisciplinary congress. We are very much looking forward to EUROSON 2014 in Tel Aviv, Israel. Please follow our invitation to this cosmopolitan city which never rests.

The succesful EFSUMB/WFUMB CEUS liver guidelines were published in our official journal "Ultraschall in der Medizin/European Journal of Ultrasound". This publication can be freely downloaded via our website www.efsumb.org (Guidelines and Good Clinical Practice Recommendations for Contrast Enhanced Ultrasound (CEUS) in the Liver - Update 2012. Ultraschall Med 2013; 34(1):11-29). The guidelines were simultanously published in the WFUMB journal (Ultrasound Med Biol) as a WFUMB-EFSUMB initiative in cooperation with representatives of AFSUMB, AIUM, ASUM, FLAUS and ICUS (2013 Feb;39(2):187-210), to strengthen the joint efforts of the federations.

The technological and clinical recommentations on the use of ultrasound elastography have been published as the first guidelines published by a multidisciplinary ultrasound society. The guidelines are part of EFSUMB's forefront worldwide efforts to improve and distribute scientific knowledge of new ultrasound techniques according to our constitution. Part 1 of the guidelines deals with the basics of ultrasound elastography, aimed at clarifying the different modalities currently on the market, which produce different types of elastography, including strain elastography and various shearwave modalities. Part 2 presents the current recommended clinical applications. It should be mentioned that a position statement on safety of elastography has been released by the ECMUS (Safety) Committee. Guidelines on ultrasound guided interventions are in preparation.

The EFSUMB website has been updated and enriched on a regular base. In preparation of my EFSUMB presidency we published an article on the use of the website (Dietrich CF, Rudd L. The EFSUMB website, a guide for better understanding. Med Ultrason 2013; 15(3):215-223) which can be downloaded via our website www.efsumb.org.

The successful EFSUMB Course Book with ten thousands of hits was updated. The printed version with coloured images is still available and can be ordered at a very cheap price via our charming secretary Lynne Rudd (efsumb@efsumb.org). The whole book is alternatively freely available on our website. The chapters are continously updated. We encourage our readers to suggest further improvements.

The EFSUMB Course Book Student Edition has been introduced with chapters on our website including videos on examination technique and anatomy. Please feel free to use and improve this material. 